\title{
Integrated Study of Transcriptome-wide m6A Methylome Confirms a Potential Mechanism for Transcriptional Regulation During Yak Adipocytes Differentiation
}

\section{Yongfeng Zhang}

Chinese Academy of Agricultural Sciences Lanzhou Institute of Husbandry and Pharmaceutical Sciences

Chunnian Liang

Chinese Academy of Agricultural Sciences Lanzhou Institute of Husbandry and Pharmaceutical Sciences

\section{Xiaoyun Wu}

Chinese Academy of Agricultural Sciences Lanzhou Institute of Husbandry and Pharmaceutical

Sciences

\section{Jie Pei}

Chinese Academy of Agricultural Sciences Lanzhou Institute of Husbandry and Pharmaceutical

Sciences

\section{Xian Guo}

Chinese Academy of Agricultural Sciences Lanzhou Institute of Husbandry and Pharmaceutical

Sciences

\section{Min Chu}

Chinese Academy of Agricultural Sciences Lanzhou Institute of Husbandry and Pharmaceutical Sciences

\section{Xuezhi Ding}

Chinese Academy of Agricultural Sciences Lanzhou Institute of Husbandry and Pharmaceutical Sciences

\section{Pengjia Bao}

Chinese Academy of Agricultural Sciences Lanzhou Institute of Husbandry and Pharmaceutical

Sciences

\section{Qudratullah Kalwar}

Chinese Academy of Agricultural Sciences Lanzhou Institute of Husbandry and Pharmaceutical

\section{Sciences}

\section{Ping Yan ( $\nabla$ pingyanlz@163.com )}

Lanzhou Institute of Husbandry and Pharmaceutical Sciences of CAAS https://orcid.org/0000-00019484-990X 


\section{Research article}

Keywords: N6-methyladenosine; MeRIP-seq; yak adipocyte; gene expression

Posted Date: October 7th, 2020

DOl: https://doi.org/10.21203/rs.3.rs-78772/v1

License: (c) (1) This work is licensed under a Creative Commons Attribution 4.0 International License. Read Full License 


\section{Abstract}

Background: Yak (Bos grunniens) is considered as an iconic symbol of Tibet and high altitude, but they suffer from malnutrition during the cold season that challenges the metabolism of energy. Adipocytes perform crucial role in maintaining the energy balance and adipocyte differentiation is a complex process involving multiple changes in expression of genes. $N^{6}$-methyladenosine $\left(\mathrm{m}^{6} \mathrm{~A}\right)$ plays an dynamic role in post-transcription gene expression regulation as the most widespread mRNA modification of the higher eukaryotes. However, currently there is no research existing on the $\mathrm{m}^{6} \mathrm{~A}$ transcriptome-wide map of bovine animals and their potential biological functions in adipocyte differentiation.

Results: We performed methylated RNA immunoprecipitation sequence (MeRIP-seq) and RNA sequence (RNA-seq) to determine the distinctions in $\mathrm{m}^{6} \mathrm{~A}$ methylation and gene expression during yak adipocyte differentiation. In yak adipocyte and preadipocyte the content of $m^{6} \mathrm{~A}$ and $\mathrm{m}^{6} \mathrm{~A}$ associated enzymes were substantially different. In the two groups, a total of $14,710 \mathrm{~m}^{6} \mathrm{~A}$ peaks and $13,388 \mathrm{~m}^{6} \mathrm{~A}$ peaks were identified. In the most part, $\mathrm{m}^{6} \mathrm{~A}$ peaks were enriched in stop codons, $3^{\prime}$-untranslated regions and coding regions. The functional enrichment exploration displayed that differentially methylated genes participated in some of the pathways associated with adipogenic metabolism. In addition to that there was a positive association between $\mathrm{m}^{6} \mathrm{~A}$ abundance and levels of gene expression, which displayed that $\mathrm{m}^{6} \mathrm{~A}$ plays vital role in modulating gene expression during yak adipocyte differentiation.

Conclusions: In short, it could be concluded that the current study provides a comprehensive explanation of the $\mathrm{m}^{6} \mathrm{~A}$ features in the yak transcriptome, offering in-depth insights into $\mathrm{m}^{6} \mathrm{~A}$ topology and associated molecular mechanisms underlying bovine adipocyte differentiation which might be helpful for further understanding its mechanisms.

\section{Background}

The yak is the major livestock breed on the Qinghai-Tibet Plateau, and is the only large ruminant domestic specie that can survive in harsh environments along with high altitude $(3,000 \sim 5,500 \mathrm{~m})$, severe cold, strong UV radiation and in low oxygen [1,2]. Because of outstanding adaptability and production output, yak performs a key role in the Tibetan region. Approximately, 15 million or more than $90 \%$ of the world's overall yak population are living in Chinese territory, ensuring daily necessities for local herders such as meat, milk, wool, skins, fuel and economic benefits [3, 4]. In the Qinghai-Tibet plateau, domestic yaks mainly grow on the natural herbage of native pastures below typical grazing conditions [5]. Owing to the seasonal variability of herbage, the yak must constantly undergo insufficient feeding during the harsh winter season (October-May), which leading to the large variations in seasonal body weight and circular rhythm 'live in summer, weighty in autumn, thin in winter and dead in spring' [6]. Consequently, the subcutaneous adipose layer of yak accumulates rapidly in the summer and early autumn, providing essential energy requirements and withstanding severe cold by selective fat catabolism in cold season 
[7]. The adaptive mechanism allows the yak as a fascinating model for research into the adipose metabolism of plateau domestic animals.

$N^{6}$-methyladenosine $\left(\mathrm{m}^{6} \mathrm{~A}\right)$ was first discovered in the 1970 s as the most prevalent internal modification of polyadenylated mRNAs and long non-coding RNAs (IncRNAs) in higher eukaryotes [8-13]. The modification of $\mathrm{m}^{6} \mathrm{~A}$ methylation is mounted by a series of $\mathrm{m}^{6} \mathrm{~A}$ methyltransferases labeled as writers: methyltransferase like 3 and 14 (METTL3 and METTL14), Wilms Tumor 1-associated protein (WTAP), VIRMA, vir-Like $\mathrm{m}^{6} \mathrm{~A}$ methyltransferase associated (KIAA1429), RNA Binding Motif Protein 15 (RBM15), and zinc finger $\mathrm{CCCH}$ domain $13(\mathrm{ZC} 3 \mathrm{H} 13)$ [14-21]. Beside, $\mathrm{m}^{6} \mathrm{~A}$ demethylases eliminate methylation from RNAs to enable a delicately dynamic equilibrium modification, and named as eraser: fat mass and obesity-associated protein (FTO) and a-ketoglutarate-dependent dioxygenase alkB homolog 5 (ALKBH5) $[22,23]$. Besides, a category of proteins called readers that can identify information of RNA methylation modification and engage in downstream mRNA translation, degradation, binding microRNA and RNAprotein interaction [24-27]. The specific proteins primarily contain the YTH domain family (YTHDF1-3) and IGF2BPs (IGF2BP1-3) [28-31]. Currently, $\mathrm{m}^{6} \mathrm{~A}$ modifications have been reported in several area of RNA metabolism, such as RNA localization, transport, splicing, stability and translation [24-27]. Moreover, previous studies described that $\mathrm{m}^{6} \mathrm{~A}$ modification of mRNA performs a significant biological function in controlling cell metabolic processes. It dominates the transition fate of cells in mammalian embryonic stem [32], regulates the differentiation and initiation of meiosis in murine spermatogonial stem cells [33], and maintains the myogenic potential in proliferative skeletal muscle progenitors [34]. In particular, FTO facilitates the differentiation of mouse pre-adipocytes by regulating alternative splicing of pre-mRNAs with adipogenesis-related genes [35]. As well as, a recent study revealed that RNA ${ }^{6} \mathrm{~A}$ modification has a potential function in the deposition of porcine adipose tissue [36]. Considering the notable functions of $\mathrm{m}^{6} \mathrm{~A}$ modification mentioned above, it is logical to assume that $\mathrm{m}^{6} \mathrm{~A}$ modification may also refer to bovine adipocyte differentiation. Previously, there is no any documented relationship lies between $\mathrm{m}^{6} \mathrm{~A}$ modification and bovine adipocyte differentiation.

Therefore, it is necessary to detect $\mathrm{m}^{6} \mathrm{~A}$ sites on transcriptome-wide level for identification the potential biological function of RNA $\mathrm{m}^{6} \mathrm{~A}$ modification. In 2012, two independent researches established a method of $\mathrm{m}^{6} \mathrm{~A}$ RNA immunoprecipitation accompanied with high-throughput sequencing (MeRIP-seq), followed the first discovery of the $N^{6}$-methyladenosine modification map to methylomes of $m^{6} \mathrm{~A}$ RNA with a resolution of 100-nucleotides [37, 38]. Simultaneously, MeRIP-seq has been used to identify the $\mathrm{m}^{6} \mathrm{~A}$ profile in humans and mice. These results revealed that $\mathrm{m}^{6} \mathrm{~A}$ is predominantly located close to stop codons, 3'-untranslated regions (3'-UTRs), and also in long internal exons and transcription start sites, indicating it performs a crucial role in the regulation of gene expression after transcription. These innovative researches proved that the construction of transcriptome-wide $\mathrm{m}^{6} \mathrm{~A}$ methylome maps is suitable for further exploring the possible biological modification features in a new area of research. 
In order to further explore the role of $\mathrm{m}^{6} \mathrm{~A}$ modification in bovine adipose metabolism, and to facilitate $\mathrm{m}^{6} \mathrm{~A}$ studies in plateau domestic livestock, we initially extracted preadipocytes from yak adipose tissue and induced them into mature adipocyte. Subsequently, the first known transcriptome-wide $\mathrm{m}^{6} \mathrm{~A}$ methylome profile was obtained in yak with MeRIP-seq, and the $\mathrm{m}^{6} \mathrm{~A}$ modification features were elucidated during yak adipocyte differentiation. Differential $\mathrm{m}^{6} \mathrm{~A}$ RNA modifications between yak preadipocyte and mature adipocyte were verified that regulate gene expressions and pathways related to energy metabolism of adipose. For our research, it can be conjectured that the $\mathrm{m}^{6} \mathrm{~A}$ modification could be a breakthrough point for exploring the yak energy metabolism.

\section{Results}

\section{The yak preadipocyte induced differentiation and global $\mathrm{m}^{6} \mathrm{~A}$ quantification}

The result of Oil Red $O$ showed that the visibility of lipid droplets in adipocytes increased significantly at day 12 compared to day 0 after induction with adipogenic agents (Fig. 1a-b). Meanwhile, the expression of adipocyte differentiation specific marker genes (PPARY, C/EBPa and FABP4) was significantly elevated on day 12 (adipocyte) than day 0 (preadipocyte) (Fig. 1c), suggesting preadipcyte full differentiation into adipocyte. Subsequently, to overview the $\mathrm{m}^{6} \mathrm{~A}$ methylation during yak adipocyte differentiation, the expression of RNA methylation-related genes were contrasted by quantitative real-time PCR (qRT-PCR) detected, including METTL3, WTAP, METTL14, FTO, ALKBH5 and YTHDF1/2/3. Comparing the group of preadipocytes (Pread0) and adipocytes (Ad), the findings showed that the expression level of methyltransferases (METTL14, WTAP and METTL3) and ALKBH5 were dramatically upregulated, while FTO was substantially downregulated and $\mathrm{m}^{6} \mathrm{~A}$-binding proteins (YTHDF2 and YTHDF3) was drastically upregulated (Fig. 1d). Furthermore, the content of $\mathrm{m}^{6} \mathrm{~A}$ in the group of adipocyte was significantly higher compared with the preadipocyte group (Fig. 1e). Thereby, we hypothesized that during yak adipocyte differentiation the difference of $\mathrm{m}^{6} \mathrm{~A}$ methylation may exist, in which furtherly discovered using MeRIPseq.

\section{Transcriptome-wide $\mathrm{m}^{6} \mathrm{~A}$-Seq revealed global $\mathrm{m}^{6} \mathrm{~A}$ modification patterns during yak adipocyte differentiation}

The yak adipocyte and preadipocyte of three biological replicates were used for transcriptome wide $\mathrm{m}^{6} \mathrm{~A}$ sequencing ( $\mathrm{m}^{6} \mathrm{~A}$-seq) and RNA-sequencing (RNA-seq) assays. In total, 12 libraries were sequenced, comprising of three replicates of preadipocyte and adipocyte for input and MeRIP samples (Additional file 1). With each MeRIP library, an average of 9.22 giga base-pair (Gb) of high-quality data was produced, and $9.49 \mathrm{~Gb}$ per input library (RNA-seq dataset). Then, we eliminated reads containing adapter pollutants, low-quality and indeterminate bases, an average of $7.17 \mathrm{~Gb}$ and $7.11 \mathrm{~Gb}$ obtained from per MeRIP and 
input libraries, respectively. The valid data were mapped to Bos_mutus genome (Version: BosGru_v2.0) using HISAT2. The proportions of mapped reads ranged from 87.96 to $96.57 \%$, correspondingly (Additional file 1). In the yak Ad group, R package exomePeak found a total of $14,710 \mathrm{~m}^{6} \mathrm{~A}$ peaks, containing transcripts of 9633 genes. Likewise, $13,388 \mathrm{~m}^{6} \mathrm{~A}$ peaks were found in the Pread 0 group corresponding to transcripts of 9142 genes (Fig. 2a-b). In addition, 5848 peaks were consistently observed in two groups, and 3964 genes within the groups were modified by $\mathrm{m}^{6} \mathrm{~A}$. Compared to the Pread0 group, the Ad group had 9226 new peaks occurring with the absence of 7904 peaks, reflecting the significant difference between Pread0 and Ad groups in global $\mathrm{m}^{6} \mathrm{~A}$ modification trends (Fig. 2a-c). $\mathrm{m}^{6} \mathrm{~A}$ methylomes were ulteriorly mapped by HOMER software to define whether RRACH motif (R represents purine, $A$ is $m^{6} A$ and $H$ is $U, A$ or $C$ ) were ubiquitous in our detected $m^{6} A$. The results of the enrichment analysis in both groups showed that $\mathrm{m}^{6} \mathrm{~A}$ RRACH consensus sequences (Fig. 2d) accorded with previous studies, in which strengthens the credibility of the $\mathrm{m}^{6} \mathrm{~A}$ peaks and confirms the presence of a prevailing methylated modification mechanism.

\section{Analysis of $\mathrm{m}^{6} \mathrm{~A}$ modification distribution in yak transcriptome}

We analyzed metagene models of $\mathrm{m}^{6} \mathrm{~A}$ peaks in the global transcriptome to identify the differential distribution of $\mathrm{m}^{6} \mathrm{~A}$ in transcripts. Our findings indicated that $\mathrm{m}^{6} \mathrm{~A}$ peaks were strongly associated with two different co-ordinates: enriched instantly the end of the $5^{\prime}$ untranslated regions ( $5^{\prime}$ UTRs), coding sequence (CDS), stop codon and starting of the $3^{\prime}$ untranslated region (3' UTRs) in Ad and Pread0 (Fig. 3a); whereas, the end peaks were noticeable abundant than beginning in CDS. Subsequently, to systematically calculate the enrichment, we investigated no overlapping transcript segments per $\mathrm{m}^{6} \mathrm{~A}$ peak with 5' UTR, CDS and 3' UTR (Fig. 3b), in which most of them were abundant in CDS. Afterwards, we explored the distribution of $\mathrm{m}^{6} \mathrm{~A}$ modified peaks with each gene, finding that almost of $60 \%$ affected genes hold only one $\mathrm{m}^{6} \mathrm{~A}$ peak and most genes conatain one to three $\mathrm{m}^{6} \mathrm{~A}$ peaks (Fig. $3 \mathrm{c}$ ).

\section{Analysis of the GO and KEGG pathways of differentially methylated genes}

Comparison was performed for the abundance of $\mathrm{m}^{6} \mathrm{~A}$ peaks between preadipocytes and adipocytes. These findings exposed that 118 markedly hypermethylated $\mathrm{m}^{6} \mathrm{~A}$ peaks and 51 substantially hypomethylated peaks were obtained ( $\mid \log 2$ (fold change) $\mid>1, p<0.05$ ) (Fig. 4a). The residual peaks of the $\mathrm{m}^{6} \mathrm{~A}$ were viewed as unaltered peaks. According to Integrative Genomics Viewer (IGV) software, the differentially methylated sites in these two groups showed altered intensity, with the GGACU motif associated $\mathrm{m}^{6} \mathrm{~A}$ peaks (Fig. 4b). Moreover, differentially methylated $\mathrm{m}^{6} \mathrm{~A}$ peaks represented genes were investigated by GO and KEGG pathway analysis, revealing the biological significance of $\mathrm{m}^{6} \mathrm{~A}$ methylation 
during yak adipocyte differentiation. GO analysis revealed that differentially methylated genes were mainly implicated with DNA-templated and regulation of transcription by RNA polymerase II (ontology: biological process), cytoplasm, nucleus and integral component of membrane (ontology: cellular component), and transcription factor and microtubule binding (ontology: molecular function) (Fig. 4c, Additional file 2). Meanwhile, the biological enrichment of KEGG indicated that the genes differently methylated were substantially related to the adipogenic metabolism regulation pathways, NOD-like receptor signaling pathway, FoxO signaling pathway, Ether lipid metabolism, cAMP signaling pathway and Hippo signaling pathway (Fig. 4d, Additional file 3).

\section{RNA-seq identification of genes differentially expressed in both groups}

An analysis of the RNA-seq dataset ( $\mathrm{m}^{6} \mathrm{~A}$-seq input library) displayed that the trends of global mRNA expression between preadipocyte and adipocyte were considerably different. There were 648 significantly different mRNAs, including 300 up-regulated and 348 down-regulated ( $\mid \log 2$ (fold change) $\mid>1, p<0.05$ ), as shown in Fig. 5a. Then, we conducted a clustered heat map to further explore the potential roles of the genes (Fig. 5b, Additional file 4). Furthermore, GO ontology and KEGG pathway were performed to analyze the differentially expressed genes. As Fig. 5c and Additional file 5 displayed, the top 20 most notable functional annotations included regulation of glucose metabolic process, canonical Wnt signaling pathway, positive regulation of cell proliferation and insulin-like growth factor ternary complex, which influenced adipocyte differentiation. Meanwhile, the pathway exploration revealed that signaling pathways regulating pluripotency of stem cells, ECM-receptor interaction, PI3K-Akt signaling pathway and FoxO signaling pathway were significantly enriched (Fig. 5d, Additional file 6), revealing that differentially expressed genes were potentially participated in adipogenic metabolism.

\section{Conjoint analysis of RIP-seq and RNA-seq data with both groups}

We found an interesting relationship of differentially methylated $\mathrm{m}^{6} \mathrm{~A}$ peaks and gene expression patterns in preadipocytes and adipocytes through cross-analysis the $\mathrm{m}^{6} \mathrm{~A}$-seq and RNA-seq results, in which a positive correlation existed in differentially methylated $\mathrm{m}^{6} \mathrm{~A}$ peaks and gene expression level (Fig. 6a). Otherwise, all genes were segregated mainly four types: 8 hypermethylated and upregulated genes termed 'hyper-up'; 7 hypomethylated and downregulated genes termed 'hypo-down'; 12 hypermethylated and whilst downregulated genes termed 'hyper-down'; and 2 hypomethylated and whilst upregulated genes termed 'hypo-up' (Fig. 6b), There were slightly more 'hyper-up' and 'hypo-down' than 'hyper-down' and 'hypo-up'. Table 1 lists the expression of genes were significantly differently ( $\mid$ log2 (fold change)| > 1 , $p<0.05)$, comprising significantly differently methylated peaks. Then, both groups were evaluated the overall expression levels of the $\mathrm{m}^{6} \mathrm{~A}$-methylated and non- ${ }^{6} \mathrm{~A}$-methylated transcripts (Fig. $6 \mathrm{c}$ ). These 
suggested that in yak adipocyte differentiation, $\mathrm{m}^{6} \mathrm{~A}$ modifications appear to have a positive association of mRNA expression. Further, we were wondering if the position of $\mathrm{m}^{6} \mathrm{~A}$ peaks on RNA transcripts or the number of $\mathrm{m}^{6} \mathrm{~A}$ peaks per transcript is correlated with the levels of gene expression. Based on $\mathrm{m}^{6} \mathrm{~A}$ modification sites, RNA transcripts were classified into subgroups. As shown in Fig. $6 \mathrm{~d}, \mathrm{~m}^{6} \mathrm{~A}$ modifications of RNA transcripts in CDS, 5'UTR or $3^{\prime} U T R$ do not clearly difference with gene expression. Through studying $\mathrm{m}^{6} \mathrm{~A}$-modified sites and relative expression levels of genes, revealing that the genes have three or four modified sites appears to be more abundant in contrast with other $\mathrm{m}^{6} \mathrm{~A}$-modified sites (Fig. 6e). 
Table 1

List of 29 genes with significant changes in $\mathrm{m}^{6} \mathrm{~A}$ and mRNA transcript abundance in yak adipocyte as compared to preadipocyte.

\begin{tabular}{|c|c|c|c|c|c|c|c|}
\hline \multirow[t]{2}{*}{ Gene name } & \multirow[t]{2}{*}{ Pattern } & \multicolumn{2}{|c|}{$\mathrm{m}^{6} \mathrm{~A}$ level change } & \multirow[b]{2}{*}{$\begin{array}{l}\text { Peak } \\
\text { end }\end{array}$} & \multicolumn{3}{|c|}{$\begin{array}{l}\text { mRNA level } \\
\text { change }\end{array}$} \\
\hline & & $\begin{array}{l}\text { Peak } \\
\text { region }\end{array}$ & $\begin{array}{l}\text { Peak } \\
\text { start }\end{array}$ & & diff.p & $\log 2(\mathrm{fc})$ & p-value \\
\hline QPRT & Hyper-up & Exon & 491048 & 491299 & 0.03 & 2.30 & 0.00 \\
\hline BCL2L11 & Hyper-up & 5' UTR & 1175002 & 1175378 & 0.01 & 2.15 & 0.04 \\
\hline PER1 & Hyper-up & 3' UTR & 235431 & 236437 & 0.01 & 2.22 & 0.00 \\
\hline KLHL29 & Hyper-up & 3' UTR & 4950507 & 4950957 & 0.01 & 1.44 & 0.02 \\
\hline KLF9 & Hyper-up & 5' UTR & 1298633 & 1299052 & 0.01 & 2.18 & 0.00 \\
\hline ZNF395 & Hyper-up & 3' UTR & 730872 & 731331 & 0.01 & 2.25 & 0.00 \\
\hline ZNF608 & Hyper-up & Exon & 980374 & 980553 & 0.01 & 2.38 & 0.00 \\
\hline MTERF4 & Hyper-up & 3' UTR & 726115 & 726234 & 0.01 & 1.32 & 0.02 \\
\hline CD247 & $\begin{array}{l}\text { Hypo- } \\
\text { down }\end{array}$ & 3' UTR & 33979 & 34575 & 0.01 & -1.78 & 0.02 \\
\hline SLC05A1 & $\begin{array}{l}\text { Hypo- } \\
\text { down }\end{array}$ & Exon & 1066324 & 1066623 & 0.01 & -2.00 & 0.01 \\
\hline AFAP1L2 & $\begin{array}{l}\text { Hypo- } \\
\text { down }\end{array}$ & Exon & 854733 & 856548 & 0.01 & -3.48 & 0.02 \\
\hline CENPF & $\begin{array}{l}\text { Hypo- } \\
\text { down }\end{array}$ & Exon & 1363460 & 1363640 & 0.01 & -3.67 & 0.00 \\
\hline USP43 & $\begin{array}{l}\text { Hypo- } \\
\text { down }\end{array}$ & 3' UTR & 129792 & 130001 & 0.01 & -3.08 & 0.00 \\
\hline ARHGEF28 & $\begin{array}{l}\text { Hypo- } \\
\text { down }\end{array}$ & Exon & 175098 & 178009 & 0.01 & -2.81 & 0.00 \\
\hline ARAP3 & $\begin{array}{l}\text { Hypo- } \\
\text { down }\end{array}$ & Exon & 442290 & 442350 & 0.01 & -3.53 & 0.00 \\
\hline PHF19 & $\begin{array}{l}\text { Hyper- } \\
\text { down }\end{array}$ & 3' UTR & 273548 & & 0.00 & -1.29 & 0.04 \\
\hline ADAMTSL1 & $\begin{array}{l}\text { Hyper- } \\
\text { down }\end{array}$ & 3' UTR & 142570 & & 0.00 & -1.99 & 0.01 \\
\hline PLD3 & $\begin{array}{l}\text { Hyper- } \\
\text { down }\end{array}$ & 3' UTR & 118422 & 118482 & 0.01 & -1.16 & 0.05 \\
\hline CDCA8 & $\begin{array}{l}\text { Hyper- } \\
\text { down }\end{array}$ & 3' UTR & 4260517 & 4260782 & 0.01 & -2.38 & 0.04 \\
\hline
\end{tabular}




\begin{tabular}{|llllllll|}
\hline PLEKHA6 & $\begin{array}{l}\text { Hyper- } \\
\text { down }\end{array}$ & Exon & 333151 & 338353 & 0.01 & -1.76 & 0.02 \\
\hline SHANK1 & $\begin{array}{l}\text { Hyper- } \\
\text { down }\end{array}$ & Exon & 403394 & 404020 & 0.01 & -2.14 & 0.00 \\
\hline SHANK1 & $\begin{array}{l}\text { Hyper- } \\
\text { down }\end{array}$ & Exon & 406035 & 406274 & 0.01 & -2.14 & 0.00 \\
\hline CENPF & $\begin{array}{l}\text { Hyper- } \\
\text { down }\end{array}$ & Exon & 1341226 & 1357574 & 0.01 & -3.67 & 0.00 \\
\hline B4GALNT1 & $\begin{array}{l}\text { Hyper- } \\
\text { down }\end{array}$ & 3' UTR & 320399 & 320607 & 0.01 & -2.38 & 0.04 \\
\hline READ4 & $\begin{array}{l}\text { Hyper- } \\
\text { down }\end{array}$ & 3' UTR & 240855 & 242598 & 0.01 & -1.50 & 0.03 \\
\hline UHRF1 & $\begin{array}{l}\text { Hyper- } \\
\text { down }\end{array}$ & 3' UTR & 274815 & 275085 & 0.01 & -1.86 & 0.02 \\
\hline FOX01 & $\begin{array}{l}\text { Hyper- } \\
\text { down }\end{array}$ & Exon & 560816 & 563952 & 0.01 & -2.62 & 0.01 \\
\hline LOC102267107 & Hypo-up & 3' UTR & 475509 & 475778 & 0.01 & 1.21 & 0.05 \\
\hline
\end{tabular}

\section{The Verification of $\mathrm{m}^{6} \mathrm{~A}$ modified Differentially Expressed Genes by Quantitative Real Time PCR}

We implemented qRT-PCR to confirm the expression of differentially methylated genes between adipocyte and preadipocyte. The mRNA expression pattern was consistent with the RNA-seq data (Fig. 7a-b), which confirms the validity of our transcriptome results.

\section{Discussion}

The harsh environment of Qinghai-Tibet plateau encourages yak to develop a special mechanism for energy metabolism. As an organ for energy metabolism, adipose tissue plays an crucial role in this process. To date, it has been found that epigenetic regulation is engaged in various biological processes including embryo development, stem cell self-renewal, DNA damage response, primary miRNA processing and energy metabolism [39-43]. In recent years, as the most extensive and plentiful internal modification on mRNAs, $\mathrm{m}^{6} \mathrm{~A}$ modification has been a major focus in the area of epigenetic regulation [44]. Furthermore, the potential roles of $\mathrm{m}^{6} \mathrm{~A}$ modification in most domestic animals, and especially for adipogenic differentiation, remained largely unknown. For the first time, our study established a comprehensive transcriptome-wide pattern of $\mathrm{m}^{6} \mathrm{~A}$ modification in yak preadipocyte and adipocyte using MeRIP-Seq technology to explore the function of $\mathrm{m}^{6} \mathrm{~A}$ modification in bovine adipogenic differentiation. 
Our findings showed that yak mRNA $\mathrm{m}^{6} \mathrm{~A}$ sites were primarily located in CDS, 5'UTRs and $3^{\prime}$ UTRs and the distribution semblable with humans and mice $[28,45]$, suggesting that in mammalian transcriptomes the overall distribution of $\mathrm{m}^{6} \mathrm{~A}$ sites is in similar manner. According to previous studies, the consitent motif pattern of "RRACH" was over-represented the $\mathrm{m}^{6} \mathrm{~A}$ motif sequence area $[38,46,47]$. Accordingly, in comparison with previous studies [37, 38], the consensus motif (GGACU) sequence in the yak transcriptome was appropriately identified revealing that RNA adenosine methylation was conserved in mammals.

Earlier studies indicated that $\mathrm{m}^{6} \mathrm{~A}$ modification is closely related to gene expression [45, 48-50]. JeanMichel Fustin et al. reported that METTL3 depletion inhibited the export mRNA [51] and Guanqun Zheng et al. reported that depletion of $A L K B H 5$ increased the export of mRNA to cytoplasm [23], suggesting $\mathrm{m}^{6} \mathrm{~A}$ promotes the export of mRNA and modulates gene expression [25]. Above results indicating a potential positive association between the degree of $\mathrm{m}^{6} \mathrm{~A}$ methylation and the transcript level. In the present study, the majority of modified $\mathrm{m}^{6} \mathrm{~A}$ genes were expressed at a medium level with a positive relationship exists in gene expression and $\mathrm{m}^{6} \mathrm{~A}$ methylated modification. Our fondings are in agreement with Chen et al., they revealed that $\mathrm{m}^{6} \mathrm{~A}$ modifications tend to have positive correlation with mRNA expression in clear cell renal cell carcinoma [49]. These findings show that $\mathrm{m}^{6} \mathrm{~A}$ methylation affects gene expression by controlling post-transcription regulation.

GO analysis explored the differentially methylated genes, which participated in the transcript regulation with a variety of transcription factors by RNA polymerase II. For example, FOXO1 identified as a Forkhead transcription factor controlling the differentiation of adipocytes [52], and many members of the ZNF family considered as the crucial eukaryotic transcription factors involved in adipogenic metabolism [53], indicating $\mathrm{m}^{6} \mathrm{~A}$ methylation participate in lipid metabolism. The KEGG pathway analysis revealed that the signaling pathway of differentially methylated genes closely related to adipose metabolism, such as FoxO signaling pathway, Ether lipid metabolism, Glycerophospholipid metabolism and Hippo signaling pathway-multiple species. Especially, FOXO1 furtherly found involved in FoxO signaling pathway which demonstrated important for adipocyte differentiation [52]. As a TEA domain family transcription factor, TEAD4 selected from Hippo signaling pathway-multiple species, in which recruits the cofactors VGLL4 and CtBP2 to inhibit murine adipogenesis [54]. To summarize the above findings, we concluded that activating the FoxO signaling pathway and Hippo signaling pathway through $\mathrm{m}^{6} \mathrm{~A}$ methylated gene may perform a key function during differentiation of yak adipocyte.

Integrated analysis of $\mathrm{m}^{6} \mathrm{~A}$-seq and mRNA-seq data exposed that 29 significant change genes existed in adipocyte group with differently methylated $\mathrm{m}^{6} \mathrm{~A}$ sites compared to preadipocyte. Several of the genes have been confirmed to regulate adipose metabolism and adipogenic differentiation, such as ZNF395, KLF9, TEAD4, FOXO1, and UHRF1. ZNF395, the mRNA of which is hypermethylated and the expression upregulated in adipocyte group compared to the preadipocyte group. As a member of the C2H-type Zinc finger proteins, ZNF395 is classified to Papillomavirus-binding factor and Huntington disease gene regulatory regionbinding protein 2 [55]. Experiments of loss and gain function demonstrated that ZNF395 
interacts with PPARG2 to modulate the transcriptional regulatory pathway that may be necessary for preadipocyte differentiation [56]. Besides, previous literature reported that mesenchymal stem cells were co-transduced with ZNF395 and PPARG2 enhanced the endogenous expression of PPARG2 and C/EBPa which are necessary for adipocyte differentiation $[56,57]$. In addition to that it was reported that Krüppellike factor $9(K L F 9)$, deemed to the basic transcription element-binding protein-1 (BTEB1) could transactivate PPARY2 to regulate adipogenesis in the 3T3-L1 cell line [58]. Besides, Kimura Hiroko et al. found that $K L F 9$ triggered the early stage of adipogenesis by promoting the $C / E B P \beta$ gene expression in 3T3-L1 cells [59]. Ubiquitin-like with PHD and RING Finger domains 1 (UHRF1) has been widely documented to promote cell proliferation [60]. Additionally, a study revealed that UHRF1 facilitates the proliferation of human adipose-derived stem cells and represses adipogenesis via inhibiting peroxisome proliferator-activated receptor $\mathrm{y}$ [61]. These findings suggested that $\mathrm{m}^{6} \mathrm{~A}$ modifications may perform an essential role during yak adipocyte differentiation.

\section{Conclusions}

Current findings displyed that the $\mathrm{m}^{6} \mathrm{~A}$ distribution patterns in the yak transcriptome and close association between $\mathrm{m}^{6} \mathrm{~A}$ methylation and adipose metabolism. Furthermore, we have also explore the correlation between the $\mathrm{m}^{6} \mathrm{~A}$ methylation and the level of gene expression, indicating a regulatory role for $\mathrm{m}^{6} \mathrm{~A}$ in adipocyte differentiation. These results provides additional knowledge of $\mathrm{m}^{6} \mathrm{~A}$ methylation in adipose tissues and it set the foundation for further understanding its possible roles and regulatory mechanisms, which could be helpful for exploration the yak adaptive mechanism in harsh environment.

\section{Methods}

\section{Pre-Adipocyte Isolation}

The Datong Yak Breeding Center (Datong County, Qinghai, China) provided three healthy 3-day-old Datong yaks. The night before slaughter, yaks were not fed. On the next morning, the yaks were humanely sacrificed by the way of electrical stunned $(90 \mathrm{~V}, 10 \mathrm{~s}$, and $50 \mathrm{~Hz})$ at a commercial slaughter facility and exsanguinated for necessary to ameliorate the suffering, according standard approved industry protocols. The subcutaneous adipose tissue was harvested according to the protocols and guidelines for animal ethics of the People's Republic of China. Yak adipocytes were isolated from subcutaneous fat tissue that was flushed with penicillin $(200 \mathrm{U} / \mathrm{mL})$ and streptomycin $(200 \mathrm{U} / \mathrm{mL})$ added to the phosphate saline buffer (HyClone, Thermo Fisher Scientific, Carlsbad, CA, USA). After that they were finely minced into about $1 \mathrm{~mm}^{3}$ pieces with an aseptic setting. The segments were digested by Type I collagenase in a continuously agitated water bath at $37^{\circ} \mathrm{C}$ for $60-90 \mathrm{~min}$. With a $40 \mu \mathrm{m}$ nylon mesh film, indigestible material was screened and the filter liquor was resuspended for $5 \mathrm{~min}$ at $1400 \mathrm{~g}$. The sediment was subsequently hatched at room temperature for $10 \mathrm{~min}$ with the erythrocyte lysis buffer $(0.154 \mathrm{M} \mathrm{NH} 4 \mathrm{Cl}$, $10 \mathrm{mM} \mathrm{KHCO}_{3}, 0.1 \mathrm{mM}$ EDTA). The cells were then filtered with $200 \mu \mathrm{m}$ nylon mesh film, and rinsed twice with a serum-free medium. After 5 minutes of centrifugation at $1400 \mathrm{~g}$, preadipocytes were harvested and 
solubilized in the growth media, including DMEM-F12 (Hyclone, USA) supplemented with $10 \%$ fetal bovine serum (FBS, Gibco, USA).

\section{Adipogenic differentiation and staining of Oil red 0}

To induce adipogenic differentiation, pre-adipocyte was induced for 2 days by adipogenic compounds composed with 3-isobuty-methylxanthine (MIX) (Sigma, USA), dexamethasone (Sigma, USA), rosiglitazone (Sigma, USA), and insulin (Sigma, USA) after cells confluence approached $70 \%$ in growth media. The medium was replaced after two days with DMEM-F12 containing $10 \%$ FBS, penicillin (200 $\mathrm{U} / \mathrm{mL})$, streptomycin $(200 \mathrm{U} / \mathrm{mL})$ and $5 \mathrm{ng} / \mathrm{mL}$ of insulin, and updated with cycles of two days, until day 12. The cells were usually flushed twice with PBS and set for $1 \mathrm{~h}$ in $4 \%$ formalin. Cells were then reacted at room temperature for 30 min with a saturated solution Oil Red 0 . And then, cells were rinsed three times with sterile water, and photographs were acquired from light microscopy.

\section{Quantitative real-time PCR}

Real-time RT-PCR was accomplished in a CFX Link Real-Time PCR Detection System, and $10 \mu \mathrm{L}$ volume of reaction consisting of $5 \mu \mathrm{L} 2$ XSYBR Premix Ex Taq II, $0.4 \mu \mathrm{L}$ primers $(10 \mu \mathrm{M})$, and $0.8 \mu \mathrm{L}$ cDNA. The reaction condition was as follows: denaturation for $30 \mathrm{~s}$ at $95^{\circ} \mathrm{C}$ followed by 35 additional cycles for $15 \mathrm{~s}$ at $94^{\circ} \mathrm{C}$, annealing for $30 \mathrm{~s}$ at $72^{\circ} \mathrm{C}$. A melting procedure with a heating rate of $0.5^{\circ} \mathrm{C} / 10 \mathrm{~s}$ was performed to create melting curves ranging from $95^{\circ} \mathrm{C}$. The gene expression levels were estimated using the $2^{-\Delta \Delta C t}$. Additional file 7 lists the sequences used for the primers.

\section{Measuring the $\mathrm{m}^{6} \mathrm{~A}$ Content}

The overall content of $m R N A m^{6} A$ was measured by a methylation quantification kit of EpiQuik RNA (Epigentek, P-9005, NY, USA). In short, a standard curve was constructed at concentrations of 0.01-0.5 ng/ $\mu \mathrm{L}$ by positive control. The equivalent RNA solution (1-8 $\mu \mathrm{L})$ and negative control were applied to the strip wells. The plate was wrapped with parafilm, hatching for $1.5 \mathrm{~h}$ at $37^{\circ} \mathrm{C}$. Then, the wells were washed three times and added the 1:1000 diluted capture antibody at room temp for $1 \mathrm{~h}$. After washing thrice, the detection antibody (1:2000 dilution) and enhancer solution were applied to every well hatched at room temp for $30 \mathrm{~min}$. After five washes, detection solutions were placed on each well and hatched for 10 minutes at room temperature to protect from light. Finally, stop solution applied to each wells and absorbance read with microplate reader at $450 \mathrm{~nm}$.

\section{MeRIP-seq and mRNA sequencing}


According to manufacturer's protocol, the total RNA was extracted using Trizol reagent (Invitrogen, CA, USA). Bioanalyzer 2100 and RNA 6000 Nano LabChip Kit (Agilent, CA, USA) with RIN number $>7.0$ were used to evaluate the total RNA quality and quantity. Nearly over 200 ug total RNA was performed to isolate Poly (A) mRNA through magnetic beads (Invitrogen) attached poly-T oligo. After purifying, poly (A) mRNA fractions are broken into 100nt long oligonucleotides using divalent cations at high temperatures. Then, the fragmentation of broken RNA were incubated in an IP buffer $(50 \mathrm{mM}$ Tris- $\mathrm{HCl}, 750 \mathrm{mM} \mathrm{NaCl}$ and $0.5 \%$ Igepal CA-630) supplied with BSA $(0.5-1 \mu \mathrm{g} / \mu \mathrm{l})$ for 2 hours at $4{ }^{\circ} \mathrm{C}$ with $\mathrm{m}^{6} \mathrm{~A}$-specific antibody (No. 202003, Synaptic Systems, Germany). The blend was further hatched with protein-A beads and eluted with the extraction buffer ( $1 \times 1 \mathrm{P}$ buffer and $\left.6.7 \mathrm{mM} \mathrm{m}{ }^{6} \mathrm{~A}\right)$, following precipitated by $75 \%$ ethanol. DUTP method was used to transform eluted $\mathrm{m}^{6} \mathrm{~A}$-containing fragments (IP) and undisposed input control fragments into final cDNA library according to a strand-specific library preparation. The paired-end libraries of insert sizes were $100 \pm 50 \mathrm{bp}$. Afterwards, we implemented the paired-end sequencing on an Illumina Novaseq ${ }^{\text {TM }} 6000$ system at LC-BIO Bio-tech Itd (Hangzhou, China), using a suggested protocol from the manufacturer.

\section{Sequencing data analysis}

First of all, in-house perl scripts and Cutadapt [62] were performed eliminate the reads containing contaminants of the adapter, bases of low quality and indeterminate. Meanwhile, the quality of the sequence was validated using fastp. The reads were mapped to the Bos_mutus genome (Version: BosGru_v2.0) by HISAT2 [63] with default parameters. Using R package exomePeak [64] identify the $\mathrm{m}^{6} \mathrm{~A}$ peaks from mapped reads of IP and input libraries with bed or bam format so as to configure for viewing on IGV software (http://www.igv.org/) or the UCSC genome browser. De novo and defined motif were identified by MEME [65] and HOMER [66], accompanied by perl scripts in the house seeking the motif with respect to peak. Called peaks were annotated using ChIPseeker [67] by intersection with gene architecture. StringTie [68] calculated the expression level of all mRNAs from input libraries, in which normalized with FPKM (FPKM=[total exon fragments/mapped reads (millions) ]). The differentially expressed mRNAs were collected by R package edgeR [69] with the $\|$ log2 (fold change) $\mid>1$ and $p$-value < 0.05. GO seq R package was performed to the Gene Ontology (GO, http://www.geneontology.org/) enrichment analysis for the differentially expressed genes [70]. Kyoto Encyclopedia of Genes and Genomes (http://www.genome.jp/kegg/) database is a major resource for learning high-level functions and utilities of biological systems. The statistical enrichment tests for genes of differential expression in the KEGG pathways were used the KOBAS software [71].

\section{Statistical analysis}

The SPSS 22 software package was used to evaluate statistics. A one-way test of variance assessed the significance of the differences between all of the groups. Statistically significant was the degree of probability * $p<0.05 ; * * p<0.01$. Values are shown as mean \pm SEM. 


\section{Abbreviations}

$\mathrm{m}^{6} \mathrm{~A}$ : N6-methyladenosine; CDS: Coding sequence; 3' UTRs: $3^{\prime}$ untranslated regions; 5' UTRs: 5' untranslated regions; IGF2BPs: insulin-like growth factor 2 mRNA-binding proteins; IGV: Integrative Genomics Viewer; GO: Gene ontology; KEGG: Kyoto Encyclopedia of Genes and Genomes; FOXO1: forkhead box 1; TEAD4: transcriptional enhancer activation domain 4; VGLL4: vestigial like family member 4; CtBP2: C-terminal-binding protein 2; ZNF395: zinc finger proteins 395; PHF19: PHD finger protein; MTERF4: mitochondrial transcription termination factor-4

\section{Declarations}

All authors have reviewed and agreed the version of the manuscript.

\section{Ethics approval and consent to participate}

Animal treatment during research was carried out in complete accordance with the protocols and guidelines for animal ethics of the People's Republic of China, and all operations were approved by the Animal Administration and Ethics Committee of Lanzhou Institute of Husbandry and Pharmaceutical Sciences, Chinese Academy of Agricultural Sciences (Permit No. SYXK-2014-0002).

\section{Consent for publication}

Not applicable.

\section{Availability of data and material}

The data was submitted to the data base of the Sequence Read Archive (SRA). The appropriate number for accession is PRJNA649748.

\section{Competing interests}

The authors have no conflicts of interest.

\section{Funding}

This work was supported by three grants. The National Natural Science Foundation of China (31972561) supplied sequencing funding and laboratory verification cost, the Agricultural Science and Technology Innovation Program (CAASASTIP-2014-LIHPS-01) and the National Beef Cattle Industry Technology \& 
System (CARS-37) supplied the source of experimental animals. The funding bodies played no role in the design of the study and collection, analysis, and interpretation of data and in writing the manuscript.

\section{Authors' contributions}

The experiments were conceived and designed by Y.Z. and P.Y. The experiments were performed by Y.Z. The experiments were assisted with J.P., X.W., X.G., M.C., P.B., X.D., C.L. The paper was written by Y.Z. and revised by $Q$. K. All authors have read and agreed to the published version of the manuscript.

\section{Acknowledgments}

We thank the Key laboratory of yak Breeding Engineering Gansu Province for experimental condition.

\section{References}

1. Durmowicz AG, Hofmeister S, Kadyraliev T, Aldashev AA, Stenmark KR: Functional and structural adaptation of the yak pulmonary circulation to residence at high altitude. J App/ Physiol 1993, 74(5):2276-2285.

2. HEATH D, WILLIAMS D, DICKINSON J: The pulmonary arteries of the yak. Cardiovasc Res 1984, 18(3):133-139.

3. Long RJ, Apori SO, Castro FB, Orskov ER: Feed value of native forages of the Tibetan Plateau of China. Anim Feed Sci Tech 1999, 80(2):101-113.

4. Dong Q, Zhao X, Ma Y, Xu S, Li Q: Live-weight gain, apparent digestibility, and economic benefits of yaks fed different diets during winter on the Tibetan plateau. Livestock Science 2006, 101(1-3):199207.

5. Long RJ, Ding LM, Shang ZH, Guo XH: The yak grazing system on the Qinghai-Tibetan plateau and its status. Rangeland J 2008, 30(2):241-246.

6. Shikui D, Ruijun L, Muyi K, Xiaogeng P, Yanjun G: Effect of urea multinutritional molasses block supplementation on liveweight change of yak calves and productive and reproductive performances of yak cows. Canadian journal of animal science 2003, 83(1):141-145.

7. Ding XZ, Guo X, Yan P, Liang CN, Bao PJ, Chu M: Seasonal and nutrients intake regulation of lipoprotein lipase (LPL) activity in grazing yak (Bos grunniens) in the Alpine Regions around Qinghai Lake. Livestock Science 2012, 143(1):29-34.

8. Desrosiers R, Friderici K, Rottman F: Identification of methylated nucleosides in messenger RNA from Novikoff hepatoma cells. Proceedings of the National Academy of Sciences 1974, 71(10):3971-3975.

9. Perry R, Kelley D: Existence of methylated messenger RNA in mouse L cells. Cell 1974, 1(1):37-42.

10. Lavi S, Shatkin AJ: Methylated simian virus 40-specific RNA from nuclei and cytoplasm of infected BSC-1 cells. Proceedings of the National Academy of Sciences 1975, 72(6):2012-2016. 
11. Wei CM, Moss B: Methylated nucleotides block $5^{1}$-terminus of vaccinia virus messenger RNA. Proceedings of the National Academy of Sciences 1975, 72(1):318-322.

12. Furuichi Y, Morgan M, Shatkin A, Jelinek W, Salditt-Georgieff M, Darnell J: Methylated, blocked 5 termini in HeLa cell mRNA. Proceedings of the National Academy of Sciences 1975, 72(5):19041908.

13. Adams JM, Cory S: Modified nucleosides and bizarre 5'-termini in mouse myeloma mRNA. Nature 1975, 255(5503):28-33.

14. Bokar J, Shambaugh M, Polayes D, Matera A, Rottman F: Purification and cDNA cloning of the AdoMet-binding subunit of the human mRNA (N6-adenosine)-methyltransferase. Rna 1997, 3(11):1233-1247.

15. Ping X-L, Sun B-F, Wang L, Xiao W, Yang X, Wang W-J, Adhikari S, Shi Y, Lv Y, Chen Y-S: Mammalian WTAP is a regulatory subunit of the RNA N6-methyladenosine methyltransferase. Cell research 2014, 24(2):177-189.

16. Schwartz S, Mumbach MR, Jovanovic M, Wang T, Maciag K, Bushkin GG, Mertins P, Ter-Ovanesyan D, Habib N, Cacchiarelli D: Perturbation of m6A writers reveals two distinct classes of mRNA methylation at internal and 5' sites. Cell Rep 2014, 8(1):284-296.

17. Liu J, Yue Y, Han D, Wang X, Fu Y, Zhang L, Jia G, Yu M, Lu Z, Deng X: A METTL3-METTL14 complex mediates mammalian nuclear RNA N 6-adenosine methylation. Nat Chem Bio/ 2014, 10(2):93-95.

18. Agarwala SD, Blitzblau HG, Hochwagen A, Fink GR: RNA methylation by the MIS complex regulates a cell fate decision in yeast. PLOS genetics 2012, 8(6).

19. Patil DP, Chen C-K, Pickering BF, Chow A, Jackson C, Guttman M, Jaffrey SR: m 6 A RNA methylation promotes XIST-mediated transcriptional repression. Nature 2016, 537(7620):369-373.

20. Wen J, Lv R, Ma H, Shen H, He C, Wang J, Jiao F, Liu H, Yang P, Tan L: Zc3h13 regulates nuclear RNA m6A methylation and mouse embryonic stem cell self-renewal. Molecular cel/ 2018, 69(6):10281038. e1026.

21. Knuckles P, Lence T, Haussmann IU, Jacob D, Kreim N, Carl SH, Masiello I, Hares T, Villaseñor R, Hess $\mathrm{D}$ : Zc3h13/Flacc is required for adenosine methylation by bridging the mRNA-binding factor Rbm15/Spenito to the m6A machinery component Wtap/FI (2) d. Genes \& development 2018, 32(56):415-429.

22. Jia G, Fu Y, Zhao X, Dai Q, Zheng G, Yang Y, Yi C, Lindahl T, Pan T, Yang YG: N6-methyladenosine in nuclear RNA is a major substrate of the obesity-associated FTO. Nat Chem Biol 2011, 7(12):885-887.

23. Zheng G, Dahl JA, Niu Y, Fedorcsak P, Huang CM, Li CJ, Vagbo CB, Shi Y, Wang WL, Song SH et al: ALKBH5 is a mammalian RNA demethylase that impacts RNA metabolism and mouse fertility. Mol Cell 2013, 49(1):18-29.

24. Roundtree IA, Evans ME, Pan T, He C: Dynamic RNA modifications in gene expression regulation. Cell 2017, 169(7):1187-1200.

25. Zhao BS, Roundtree IA, He C: Post-transcriptional gene regulation by mRNA modifications. Nat Rev Mol Cell Biol 2017, 18(1):31-42. 
26. Nachtergaele S, He C: The emerging biology of RNA post-transcriptional modifications. Rna Biol 2017, 14(2):156-163.

27. Liu N, Pan T: N 6-methyladenosine-encoded epitranscriptomics. Nat Struct Mol Biol 2016, 23(2):98.

28. Dominissini D, Moshitch-Moshkovitz S, Schwartz S, Salmon-Divon M, Ungar L, Osenberg S, Cesarkas $\mathrm{K}$, Jacob-Hirsch J, Amariglio N, Kupiec M: Topology of the human and mouse $m 6$ A RNA methylomes revealed by $\mathrm{m} 6$ A-seq. Nature 2012, 485(7397):201-206.

29. Wang X, Lu Z, Gomez A, Hon GC, Yue Y, Han D, Fu Y, Parisien M, Dai Q, Jia G: N 6-methyladenosinedependent regulation of messenger RNA stability. Nature 2014, 505(7481):117-120.

30. Wang X, Zhao BS, Roundtree IA, Lu Z, Han D, Ma H, Weng X, Chen K, Shi H, He C: N6-methyladenosine modulates messenger RNA translation efficiency. Cell 2015, 161(6):1388-1399.

31. Luo S, Tong L: Molecular basis for the recognition of methylated adenines in RNA by the eukaryotic YTH domain. Proceedings of the National Academy of Sciences 2014, 111(38):13834-13839.

32. Batista PJ, Molinie B, Wang J, Qu K, Zhang J, Li L, Bouley DM, Lujan E, Haddad B, Daneshvar K: m6A RNA modification controls cell fate transition in mammalian embryonic stem cells. Cell stem cell 2014, 15(6):707-719.

33. Xu K, Yang Y, Feng GH, Sun BF, Chen JQ, Li YF, Chen YS, Zhang XX, Wang CX, Jiang LY et al: Mett|3mediated $\mathrm{m}(6) A$ regulates spermatogonial differentiation and meiosis initiation. Cell research 2017, 27(9):1100-1114.

34. Kudou K, Komatsu T, Nogami J, Maehara K, Harada A, Saeki H, Oki E, Maehara Y, Ohkawa Y: The requirement of Mett|3-promoted MyoD mRNA maintenance in proliferative myoblasts for skeletal muscle differentiation. Open Bio/ 2017, 7(9).

35. Zhao X, Yang Y, Sun BF, Shi Y, Yang X, Xiao W, Hao YJ, Ping XL, Chen YS, Wang WJ et al: FTOdependent demethylation of N6-methyladenosine regulates mRNA splicing and is required for adipogenesis. Cell research 2014, 24(12):1403-1419.

36. Tao X, Chen J, Jiang Y, Wei Y, Chen Y, Xu H, Zhu L, Tang G, Li M, Jiang A et al: Transcriptome-wide N6-methyladenosine methylome profiling of porcine muscle and adipose tissues reveals a potential mechanism for transcriptional regulation and differential methylation pattern. Bmc Genomics 2017, 18(1).

37. Dominissini D, Moshitch-Moshkovitz S, Schwartz S, Salmon-Divon M, Ungar L, Osenberg S, Cesarkas $\mathrm{K}$, Jacob-Hirsch J, Amariglio N, Kupiec M et al: Topology of the human and mouse m6A RNA methylomes revealed by m6A-seq. Nature 2012, 485(7397):201-206.

38. Meyer KD, Saletore Y, Zumbo P, Elemento O, Mason CE, Jaffrey SR: Comprehensive analysis of mRNA methylation reveals enrichment in 3' UTRs and near stop codons. Cell 2012, 149(7):1635-1646.

39. Shi L, Wu J: Epigenetic regulation in mammalian preimplantation embryo development. Reprod Biol Endocrin 2009, 7(1):59.

40. Wu H, Sun YE: Epigenetic regulation of stem cell differentiation. Pediatric research 2006, 59(4):21-25. 
41. Li D-Q, Nair SS, Kumar R: The MORC family: new epigenetic regulators of transcription and DNA damage response. Epigenetics 2013, 8(7):685-693.

42. Wang Z, Yao H, Lin S, Zhu X, Shen Z, Lu G, Poon WS, Xie D, Lin MC-m, Kung H-f: Transcriptional and epigenetic regulation of human microRNAs. Cancer Lett 2013, 331(1):1-10.

43. Donohoe DR, Bultman SJ: Metaboloepigenetics: interrelationships between energy metabolism and epigenetic control of gene expression. J Cell Physiol 2012, 227(9):3169-3177.

44. Niu Y, Zhao X, Wu Y-S, Li M-M, Wang X-J, Yang Y-G: N6-methyl-adenosine (m6A) in RNA: an old modification with a novel epigenetic function. Genomics, proteomics \& bioinformatics 2013, 11(1):817.

45. Meyer KD, Saletore Y, Zumbo P, Elemento O, Mason CE, Jaffrey SR: Comprehensive analysis of mRNA methylation reveals enrichment in 3' UTRs and near stop codons. Cel/ 2012, 149(7):1635-1646.

46. Harper JE, Miceli SM, Roberts RJ, Manley JL: Sequence specificity of the human mRNA N6adenosine methylase in vitro. Nucleic Acids Res 1990, 18(19):5735-5741.

47. Dominissini D, Moshitch-Moshkovitz S, Schwartz S, Salmon-Divon M, Ungar L, Osenberg S, Cesarkas $\mathrm{K}$, Jacob-Hirsch J, Amariglio N, Kupiec M: Topology of the human and mouse m6A RNA methylomes revealed by m6A-seq. Nature 2012, 485(7397):201-206.

48. Fu Y, Dominissini D, Rechavi G, He C: Gene expression regulation mediated through reversible m 6 A RNA methylation. Nat Rev Genet 2014, 15(5):293.

49. Chen Y, Zhou C, Sun Y, He X, Xue D: m6A RNA modification modulates gene expression and cancerrelated pathways in clear cell renal cell carcinoma. Epigenomics-Uk 2020, 12(2):87-99.

50. Yue Y, Liu J, He C: RNA N6-methyladenosine methylation in post-transcriptional gene expression regulation. Genes \& development 2015, 29(13):1343-1355.

51. Jean-Michel F, Masao D, Yoshiaki Y, Hayashi H, Shinichi N, Minoru Y, Takayuki I, Masaki Suimye M, Hideaki K, Ichiro M: RNA-Methylation-Dependent RNA Processing Controls the Speed of the Circadian Clock. Cell 2013, 155(4):793-806.

52. Nakae J, Kitamura T, Kitamura Y, Biggs III WH, Arden KC, Accili D: The forkhead transcription factor Foxo1 regulates adipocyte differentiation. Developmental cell 2003, 4(1):119-129.

53. Wei S, Zhang L, Zhou X, Du M, Jiang Z, Hausman GJ, Bergen WG, Zan L, Dodson MV: Emerging roles of zinc finger proteins in regulating adipogenesis. Cell Mol Life Sci 2013, 70(23):4569-4584.

54. Zhang W, Xu J, Li J, Guo T, Jiang D, Feng X, Ma X, He L, Wu W, Yin M: The TEA domain family transcription factor TEAD4 represses murine adipogenesis by recruiting the cofactors VGLL4 and CtBP2 into a transcriptional complex. J Biol Chem 2018, 293(44):17119-17134.

55. Tanaka K, Shouguchi-Miyata J, Miyamoto N, Ikeda J-E: Novel nuclear shuttle proteins, HDBP1 and HDBP2, bind to neuronal cell-specific cis-regulatory element in the promoter for the human Huntington's disease gene. J Biol Chem 2004, 279(8):7275-7286.

56. Hasegawa R, Tomaru Y, de Hoon M, Suzuki H, Hayashizaki Y, Shin JW: Identification of ZNF395 as a novel modulator of adipogenesis. Exp Cell Res 2013, 319(3):68-76. 
57. Sichtig N, Körfer N, Steger G: Papillomavirus binding factor binds to SAP30 and represses transcription via recruitment of the HDAC1 co-repressor complex. Arch Biochem Biophys 2007, 467(1):67-75.

58. Pei H, Yao Y, Yang Y, Liao K, Wu J: Krüppel-like factor KLF9 regulates PPAR Y transactivation at the middle stage of adipogenesis. Cell Death \& Differentiation 2011, 18(2):315-327.

59. Kimura H, Fujimori K: Activation of early phase of adipogenesis through Kruppel-like factor KLF9mediated, enhanced expression of CCAAT/enhancer-binding protein beta in 3T3-L1 cells. Gene 2014, 534(2):169-176.

60. Chen K, Guo Z, Luo Y, Yuan J, Mo Z: UHRF1 Promotes Proliferation of Human Adipose-Derived Stem Cells and Suppresses Adipogenesis via Inhibiting Peroxisome Proliferator-Activated Receptor gamma. Biomed Res Int 2019, 2019:9456847.

61. Chen K, Guo Z, Luo Y, Yuan J, Mo Z: UHRF1 Promotes Proliferation of Human Adipose-Derived Stem Cells and Suppresses Adipogenesis via Inhibiting Peroxisome Proliferator-Activated Receptor $Y$. Biomed Res Int 2019, 2019.

62. Martin M: Cutadapt removes adapter sequences from high-throughput sequencing reads. EMBnet journal 2011, 17(1):10-12.

63. Kim D, Langmead B, Salzberg SL: HISAT: a fast spliced aligner with low memory requirements. Nature methods 2015, 12(4):357-360.

64. Meng J, Lu Z, Liu H, Zhang L, Zhang S, Chen Y, Rao MK, Huang Y: A protocol for RNA methylation differential analysis with MeRIP-Seq data and exomePeak R/Bioconductor package. Methods 2014, 69(3):274-281.

65. Bailey TL, Boden M, Buske FA, Frith M, Grant CE, Clementi L, Ren J, Li WW, Noble WS: MEME SUITE: tools for motif discovery and searching. Nucleic Acids Res 2009, 37(suppl_2):W202-W208.

66. Heinz S, Benner C, Spann N, Bertolino E, Lin YC, Laslo P, Cheng JX, Murre C, Singh H, Glass CK: Simple combinations of lineagedetermining transcription factors prime cis-regulatory elements required for macrophage and B cell identities. Molecular cel/ 2010, 38(4):576-589.

67. Yu G, Wang L-G, He Q-Y: ChIPseeker: an R/Bioconductor package for ChIP peak annotation, comparison and visualization. Bioinformatics 2015, 31(14):2382-2383.

68. Pertea M, Pertea GM, Antonescu CM, Chang T-C, Mendell JT, Salzberg SL: StringTie enables improved reconstruction of a transcriptome from RNA-seq reads. Nature biotechnology 2015, 33(3):290.

69. Robinson MD, McCarthy DJ, Smyth GK: edgeR: a Bioconductor package for differential expression analysis of digital gene expression data. Bioinformatics 2010, 26(1):139-140.

70. Young MD, Wakefield MJ, Smyth GK, Oshlack A: Gene ontology analysis for RNA-seq: accounting for selection bias. Genome Biol 2010, 11(2):R14.

71. Xie C, Mao X, Huang J, Ding Y, Wu J, Dong S, Kong L, Gao G, Li CY, Wei L: KOBAS 2.0: a web server for annotation and identification of enriched pathways and diseases. Nucleic Acids Res 2011, 39(Web Server issue):W316-322. 


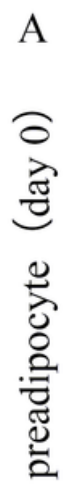
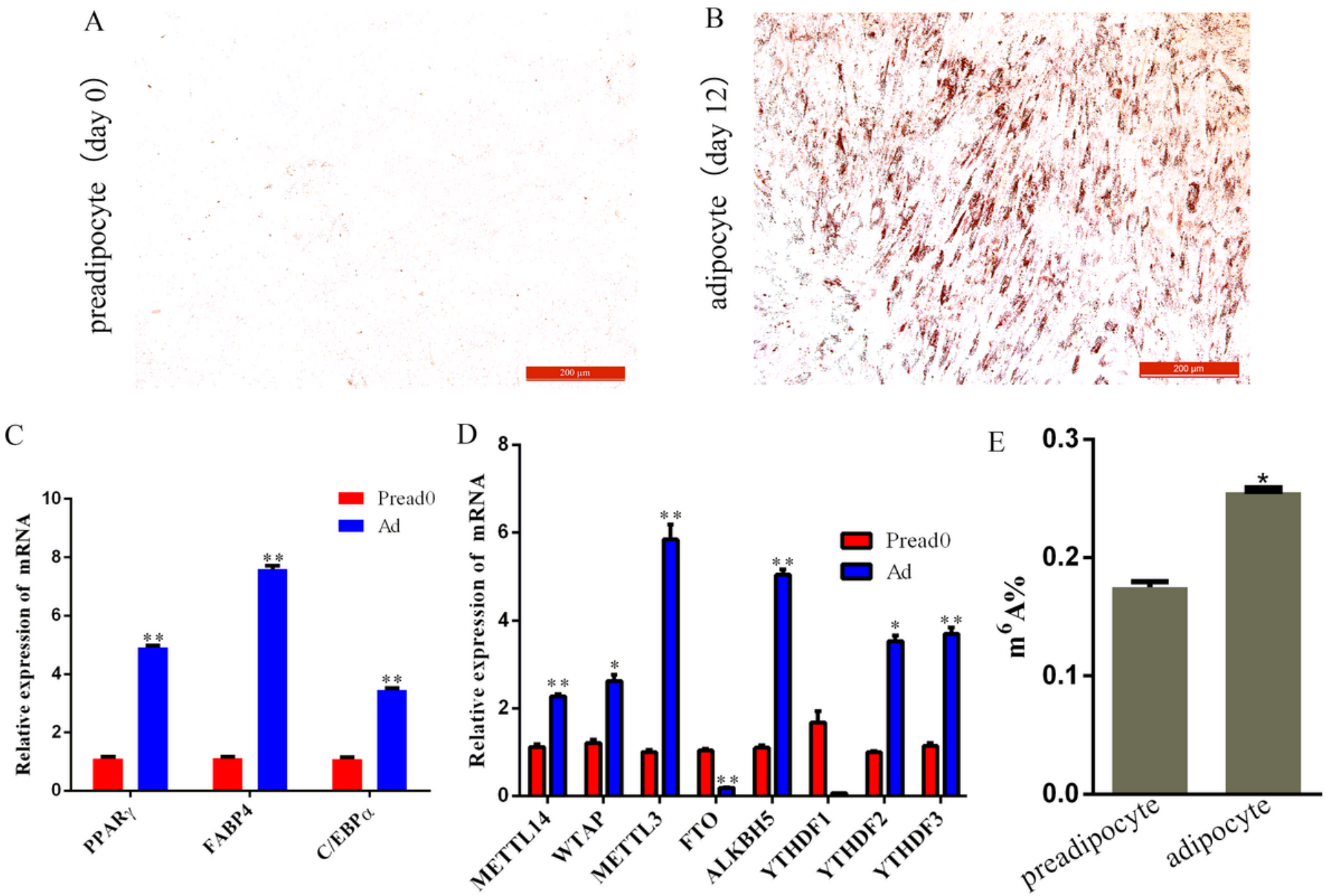

Figure 1

Preadipocyte induced differentiation and detection of m6A level between preadipocyte and adipocyte. (ab) Preadipocytes and adipocytes dyed with Oil red O. (c) Relative expression of PPARy, C/EBPa, and FABP4 between preadipocyte (day 0) and adipocyte (day 12). (d) The mRNA expression level of methyltransferases (METTL14, WTAP and METTL3), demethylases (FTO and ALKBH5), and m6A-binding proteins (YTHDF1, YTHDF2 and YTHDF3). (e) m6A abundance between the preadipocytes and adipocytes. (SEM, * $p<0.05 ; * \star p<0.01)$. 

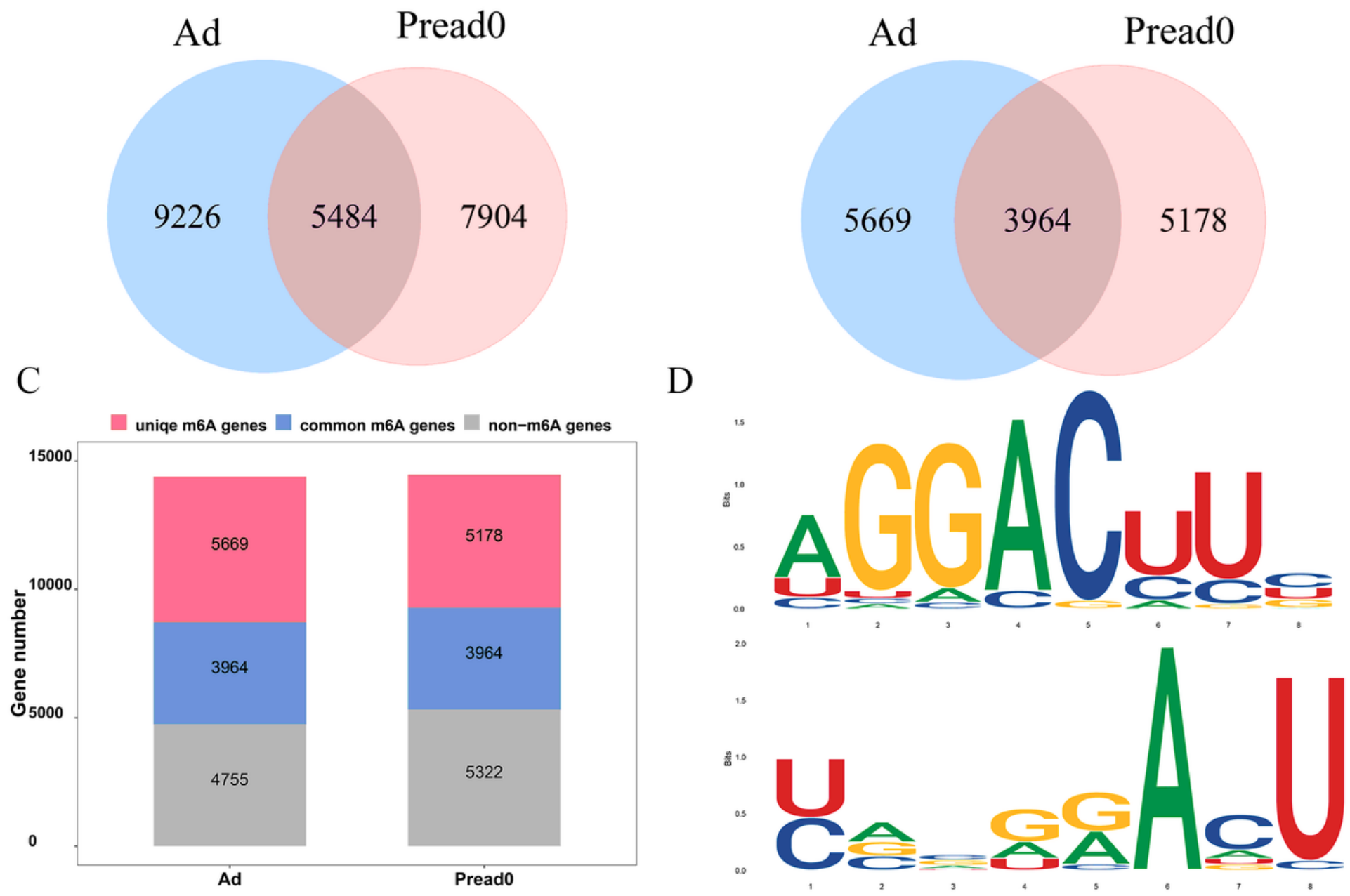

Figure 2

m6A-seq transcriptome-wide, and m6A peak analysis. (a) Number of common and specific m6A peaks in groups of preadipocyte and adipocyte. (b) Venn diagram showing the m6A peaks for transcripts of two group. (c) Profile of m6A-modified genes discovered in m6A-seq. (d) The top motifs enriched from m6A peaks identified from the groups of adipocyte and preadipocyte. 
A
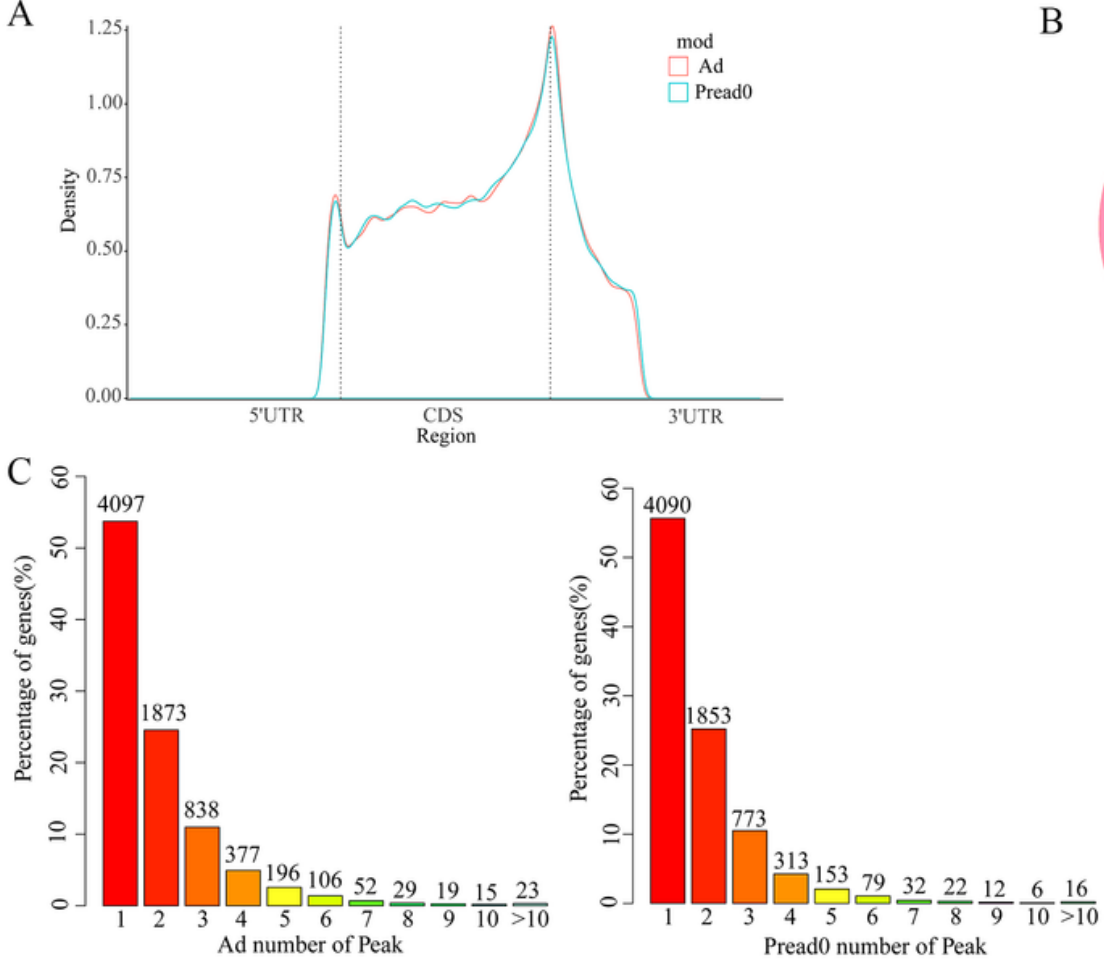

B

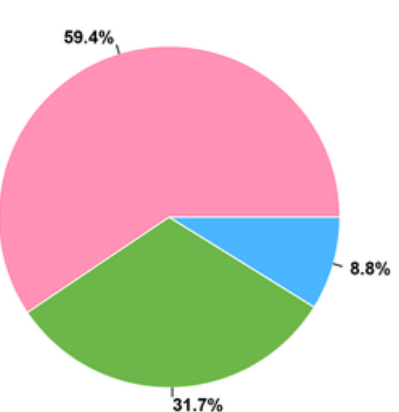

Ad total $\mathrm{m}^{6} \mathrm{~A}$ distribution

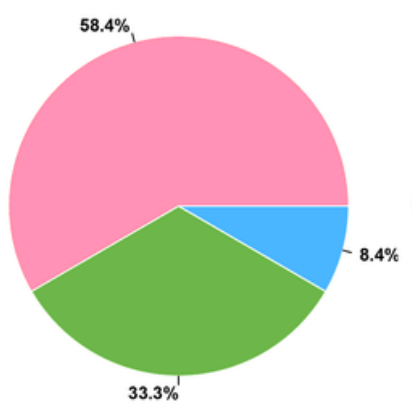

Pread0 total $\mathrm{m}^{6}$ Adistribution

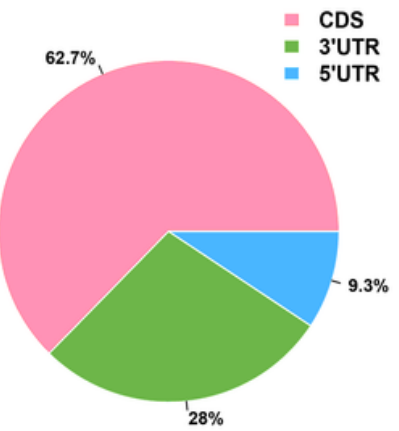

Ad unique $\mathrm{m}^{6} \mathrm{~A}$ distribution

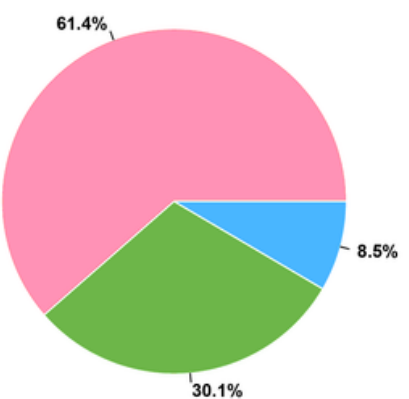

Pread0 unique $\mathrm{m}^{6} \mathrm{~A}$ distribution

\section{Figure 3}

m6A methylome distributed on yak transcripts. (a) m6A peaks enriched with transcripts. Transcript is separated into three parts comprising 5' untranslated region, coding sequence and 3' untranslated region. (b) The proportion of m6A peak distribution in the adipocyte and preadipocyte regions (c) Proportion of genes possessing m6A peaks with different numbers. 
A
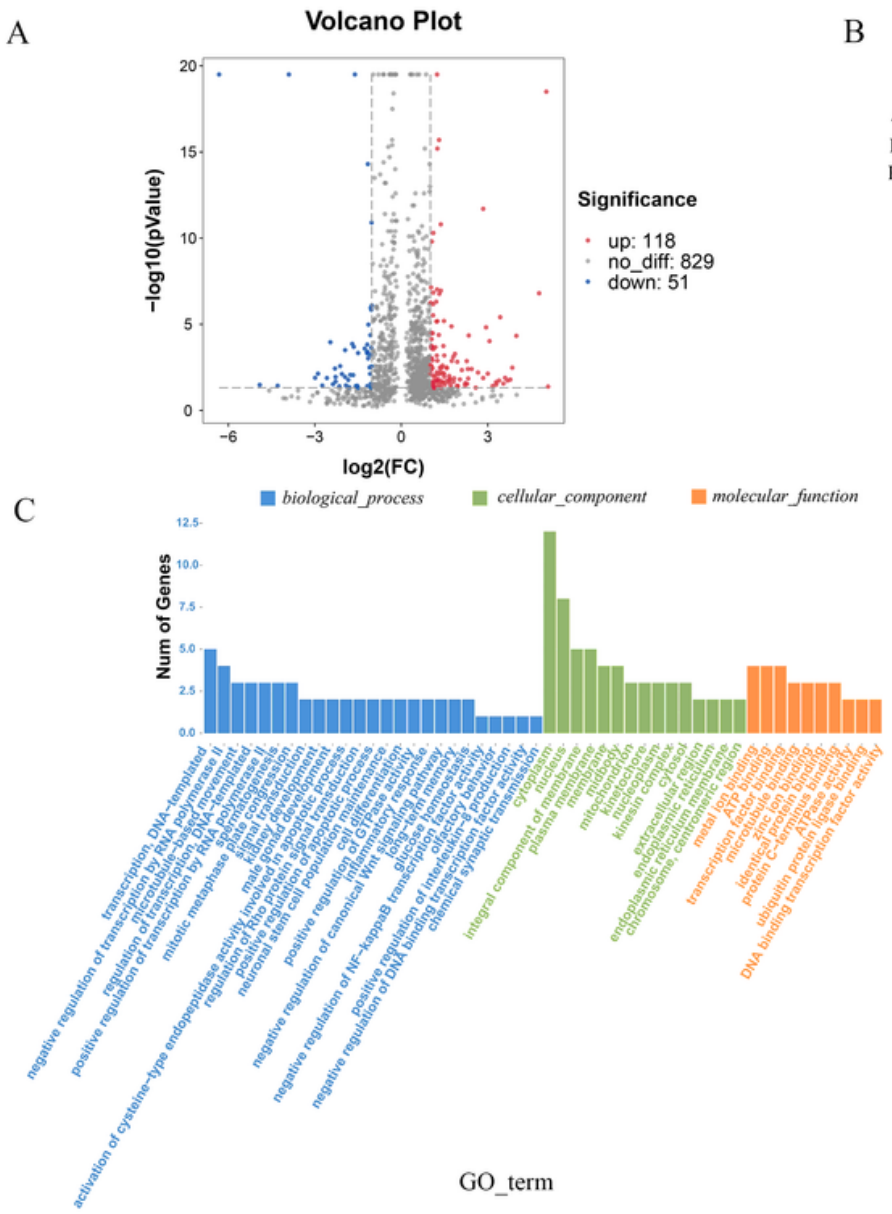

B

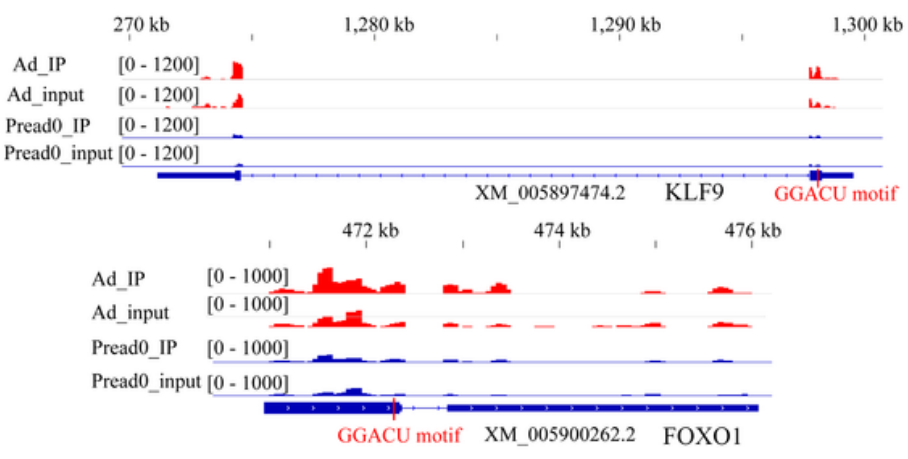

$\mathrm{D}$

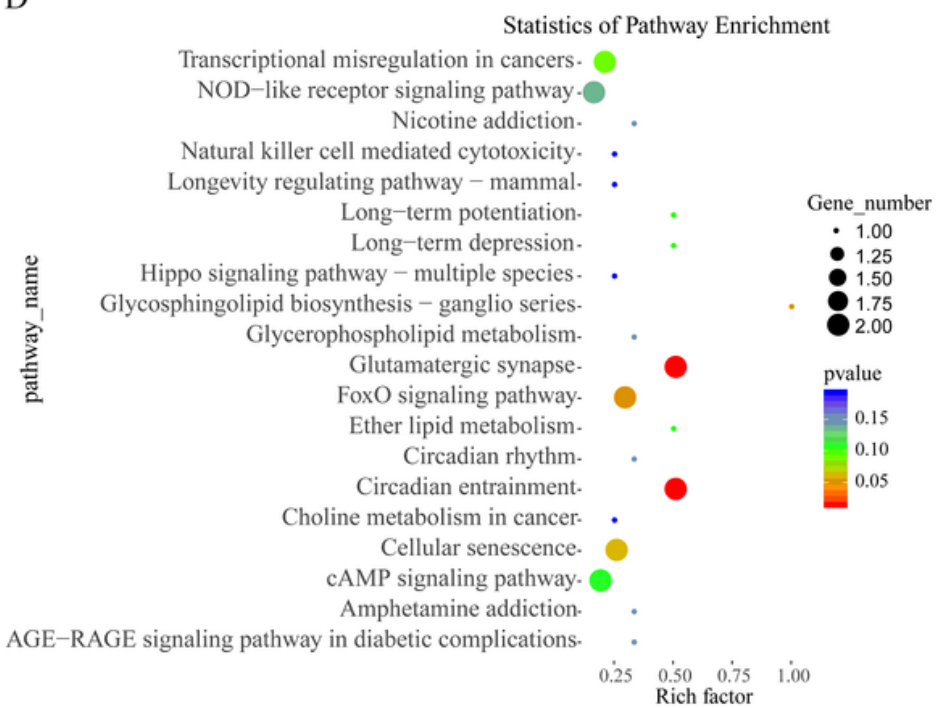

\section{Figure 4}

The alteration of global m6A modification in adipocyte compared with preadipocyte. (a) Volcano plots showing different m6A peaks (fold change $\geq 2$ and $p<0.05$ ) between preadipocyte and adipocyte. (b) The abundance of m6A on KLF9 and F0X01 mRNA transcripts observed by m6A-seq in preadipocyte and adipocyte. (c) GO terms of genes with differential m6A peaks between preadipocyte and adipocyte. (d) The top20 markedly enriched pathways for the genes of differential peaks between preadipocyte and adipocyte. 


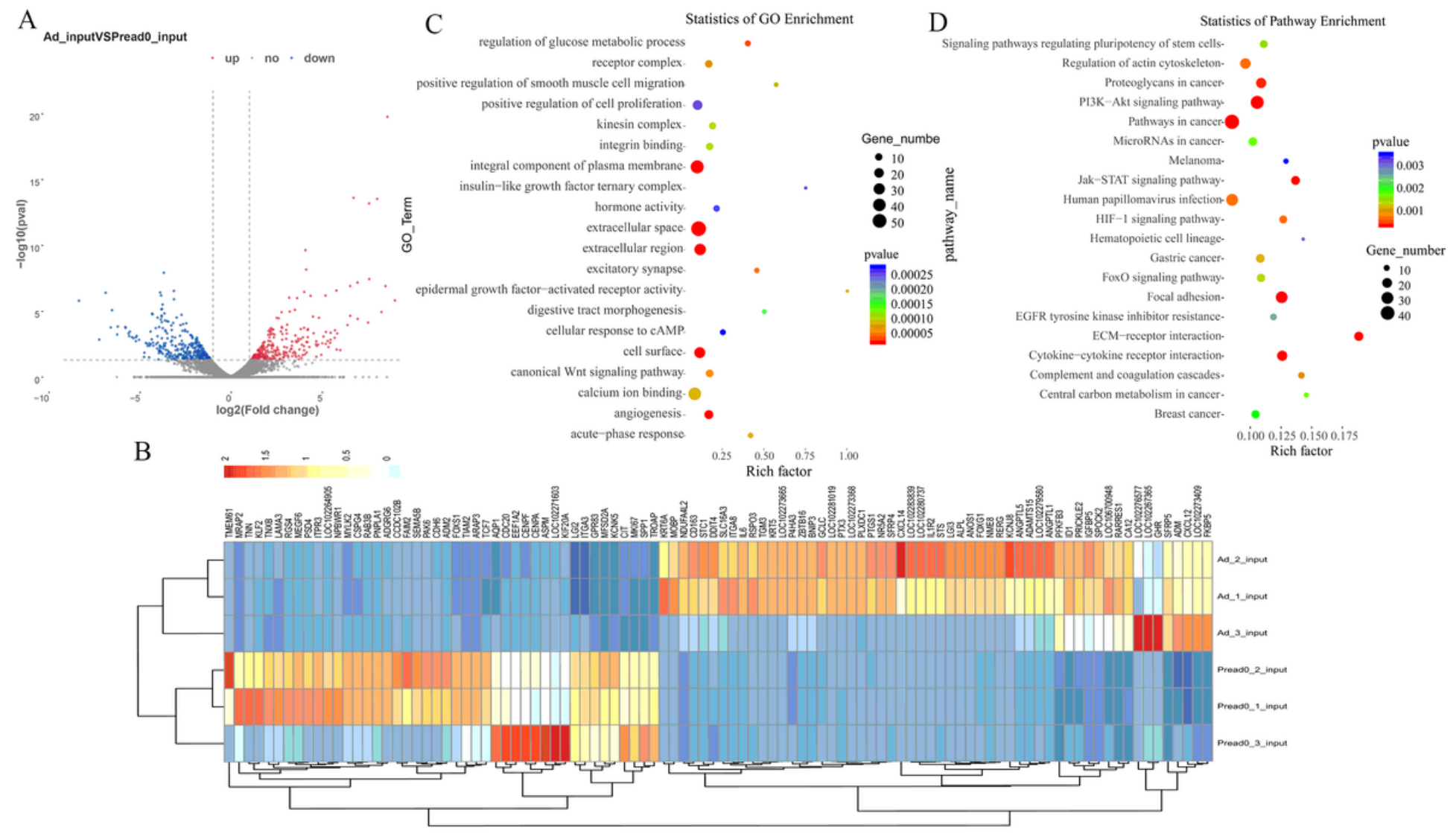

Figure 5

RNA-seq analyzes of genes differentially expressed between preadipocyte and adipocyte. (a) Volcano plots illustrating the differentially expressed genes. (b) Clustered heat map for comparing preadipocyte and adipocyte with the top 100 most differentially expressed genes. (c) The top 20 significantly GO enrichment terms for significantly differentially expressed genes. (d) The top 20 enriched pathways of dramatically differentially expressed genes. 


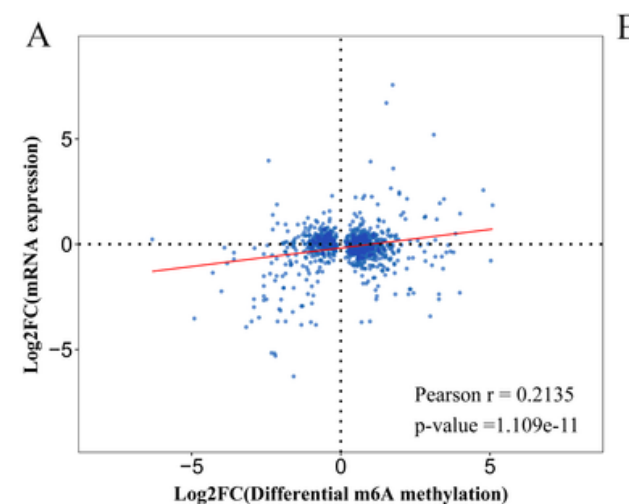

D

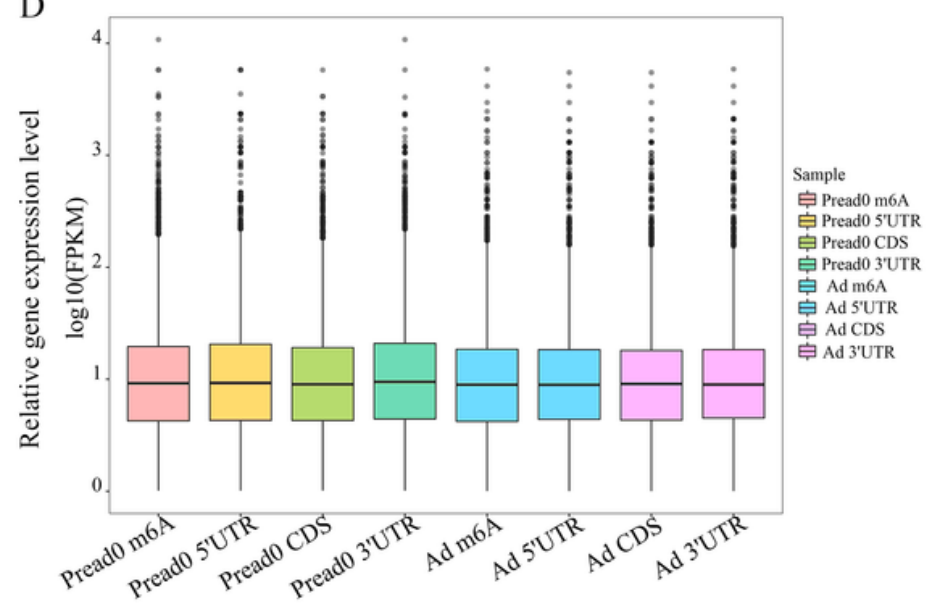

B

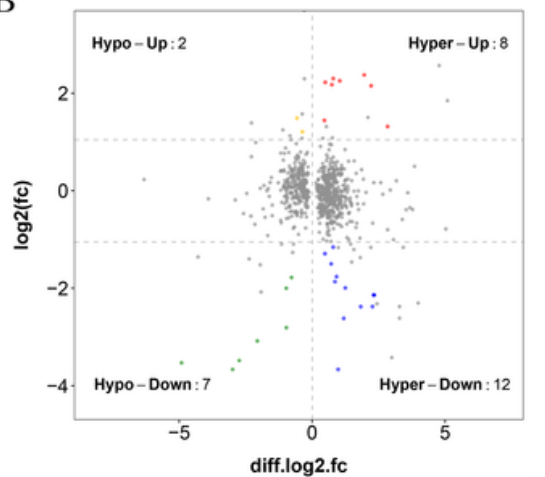

$\mathrm{C}$

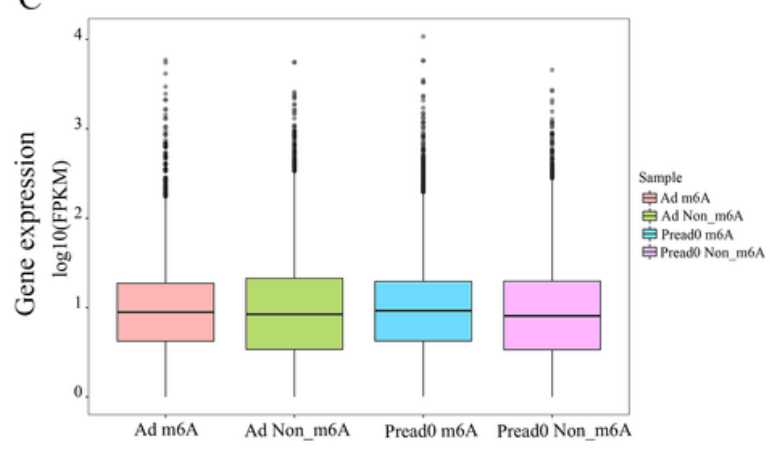

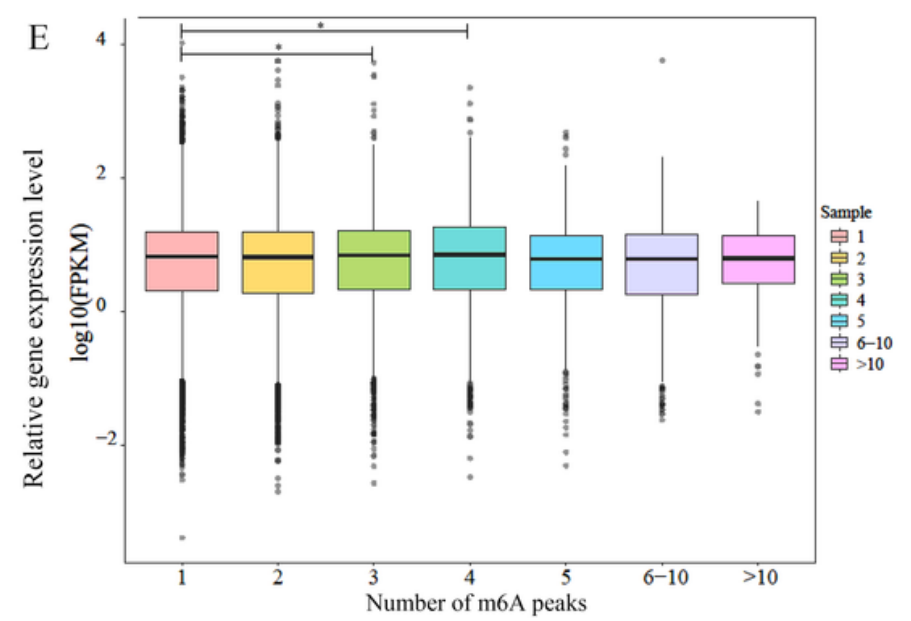

Figure 6

Conjoint analysis of differentially methylated genes and differentially expressed genes. (a) Dot plot of Log2 fold change (FC) (mRNA expression) versus Log2 FC (differential m6A methylation) revealing a positive association between total m6A methylation and level of mRNA expression (Pearson $r=0.2135$; $p$ value $=1.109 \mathrm{e}-11$ ). (b) Four quadrant plot showing differentially expressed genes with differentially methylated m6A peaks. (c) The holistic expression levels of the transcripts with m6A-methylated and non-m6A-methylated in different groups. (d) For all m6A peaks, the position of m6A peaks for RNA transcripts and gene relative expression level. (e) Relative mRNA transcript expression level with different number of m6A peaks. ${ }^{*} \mathrm{p}<0.05$ compared with the m6A peak $=1$. 

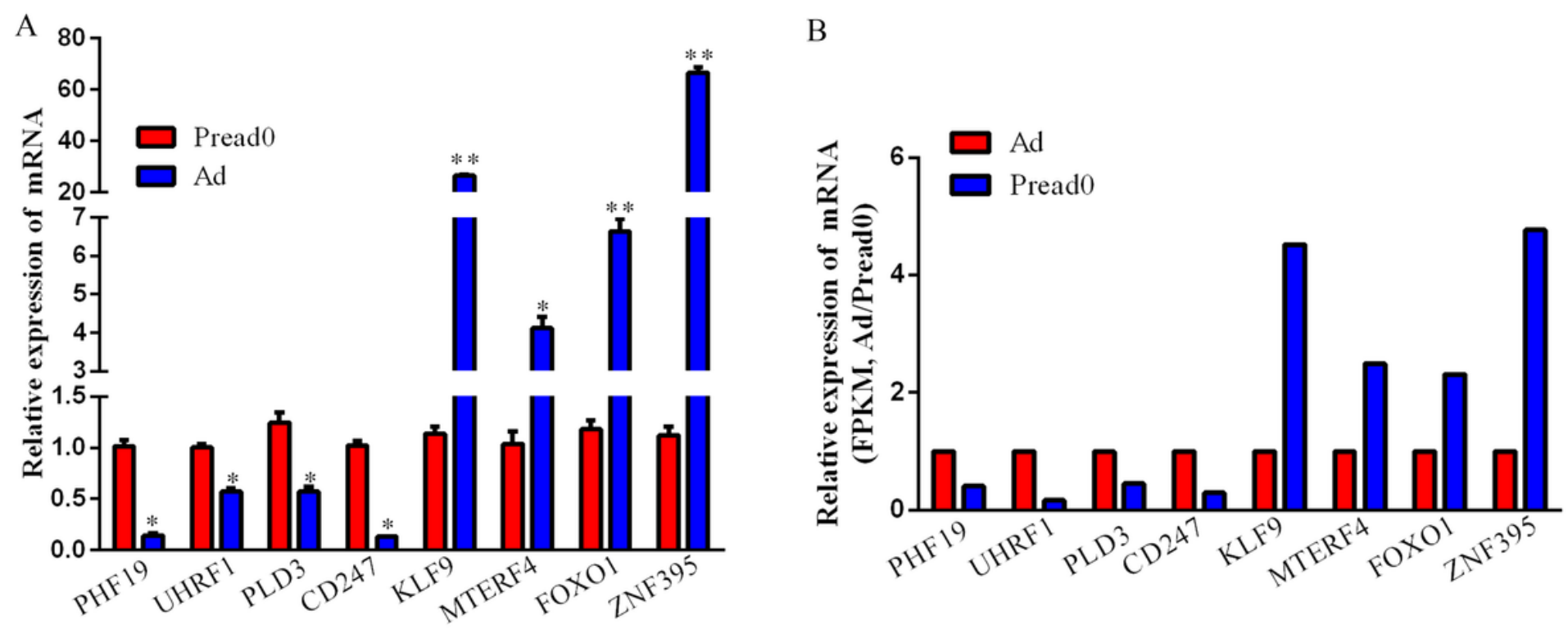

Figure 7

qPCR tests of eight differentially expressed genes modified by m6A in preadipocyte and adipocyte. (a) The relative mRNA levels were determined by qPCR of eight genes in both groups and (b) the genes change levels based on RNA-seq data.

\section{Supplementary Files}

This is a list of supplementary files associated with this preprint. Click to download.

- Additionalfile7.docx

- Additionalfile6.xlsx

- Additionalfile5.xlsx

- Additionalfile4.xIsx

- Additionalfile3.xIsx

- Additionalfile2.xIsx

- Additionalfile1.docx 